\title{
GEDÄCHTNISSREDE
}

\author{
AUF \\ ERNS'T CUR'TIUS. \\ VON
}

ULRICH KÖHLER.

AUS DEN ABHANIILUNGEN IER KÖNIGL. PREUSS. AKADEMIE DER WISSENSCHAYTEN ZU BERIIN VOM JAHRE 1897.

\section{BERLIN 1897.}

VERLAG DER KÖNIGL. AKADEMIE DER WISSENSCHAFTEN.

IN COMMISSION BEI GEORG REIMER. 
Gehalten in der öffentlichen Sitzung am 1. Juli 1897 [Sitzungsherichte St. XXXIII. S. 712].

Zum Druck eingereicht am gleichen Tage, ausgegeben am 7. Juli 1897. 